\title{
Selective recognition in potentiometric transduction of amoxicillin by molecularly imprinted materials
}

\author{
J. Rafaela L. Guerreiro • M. Goreti F. Sales • \\ Felismina T. C. Moreira • Tânia S. R. Rebelo
}

\begin{abstract}
The indiscriminate use of antibiotics in foodproducing animals has received increasing attention as a contributory factor in the international emergence of antibiotic-resistant bacteria (Woodward in Pesticide, veterinary and other residues in food, CRC Press, Boca Raton, 2004). Numerous analytical methods for quantifying antibacterial residues in edible animal products have been developed over years (Woodward in Pesticide, veterinary and other residues in food, CRC Press, Boca Raton, 2004; Botsoglou and Fletouris in Handbook of food analysis, residues and other food component analysis, Marcel Dekker, Ghent, 2004). Being Amoxicillin (AMOX) one of those critical veterinary drugs, efforts have been made to develop simple and expeditious methods for its control in food samples. In literature, only one AMOX-selective electrode has been reported so far. In that work, phosphotungstate:amoxycillinium ion exchanger was used as electroactive material (Shoukry et al. in Electroanalysis 6:914-917, 1994). Designing new materials based on molecularly imprinted polymers (MIPs) which are complementary to the size and charge of AMOX could lead to very selective interactions, thus enhancing the selectivity of the sensing unit. AMOXselective electrodes used imprinted polymers as electroactive materials having AMOX as target molecule to design a biomimetic imprinted cavity. Poly(vinyl chloride), sensors of methacrylic acid displayed Nernstian slopes $(60.7 \mathrm{mV} /$ decade $)$ and low detection limits $\left(2.9 \times 10^{-5}\right.$ $\mathrm{mol} / \mathrm{L}$ ). The potentiometric responses were not affected by
\end{abstract}

pH within 4-5 and showed good selectivity. The electrodes were applied successfully to the analysis of real samples.

Keywords Amoxicillin · Molecularly imprinted sensors · Potentiometry · Drugs

\section{Introduction}

Aquaculture is one of the fastest growing food-producing sectors, supplying approximately $40 \%$ of the world's fish food [4]. A wide range of antimicrobial compounds are often used not only for prevention or treatment of diseases, but also as growth promoters during the production of animals for human consumption. The potential consequences of this antibiotic use are the development of antibiotic-resistant microorganisms, multiple antibiotic resistance, resistance transfer to pathogenic bacteria, and reduced efficacy of antibiotic treatment for diseases in humans caused by resistant pathogens [5].

$\beta$-Lactamic antibiotics, like penicillins (including here Amoxicillin, AMOX), cephalosporins, cephamycins, and carbapenems are important antimicrobial agents that are widely used to treat human infections and animal diseases in aquaculture due to its broad spectrum and low cost $[6,7]$. AMOX is active against a wide range of Grampositive and a limited range of Gram-negative organisms. It is usually the drug of choice within the class because it is better absorbed, following oral administration, than other b-lactam antibiotics [8]. AMOX has a bactericidal action and inhibits the bacterial cell wall biosynthesis by binding the enzymes that produce the protein cell wall $[9,10]$. However, the improper applications of antibiotics may lead to the occurrence of residues in food supplies. Farm animals treated with antibiotics required to be held for a 
specific withdrawal period until all residues are depleted to a safe level before the animal tissue or milk can be used for human consumption [11].

The use of antibiotics in aquaculture increased the concern not only about food security but also about the environment. When antibiotics and other therapeutic chemicals are added to feed, they can affect organisms for which they were not intended, for example, when the drugs are released in water, uneaten pellets decompose [12]. Nonetheless, many drugs used in fish farms have been found to have minimal (if any) deleterious effects on the aquatic environment [13]. For that reason, analytical methods are required for monitoring residues of this compound in aquatic environment.

Several analytical procedures are suggested in literature for AMOX, based on spectroscopy [14-19], capillary electrophoresis [20, 21], electrochemical methods [22-24] and high-performance liquid chromatography (HPLC) [25-29] associated with fluorescence [30], UV [31, 32] and fluorimetric [33] detections employing pre-column [34] or post-column derivatization [35].

Although some of these methods offered very good sensitivity, accuracy, and precision for the determination of AMOX, they present some disadvantages in routine control procedures. Routine determinations need quick answers, and these techniques are time-consuming, require complex instrumentation, large amount of high purity organic solvents, and long times for equilibration and derivatization treatment. Therefore, it is important to set up a simple, rapid and expeditious method that may provide specific and sensitive measurements of AMOX for its screening in food samples.

Molecularly imprinted polymers (MIPs) are capable of recognizing a specific molecule or a family of compounds, in a simple and rapid way. This technique is based on hostguest interactions and is meant for specific binding just as antibody/antigen [36, 37]. MIPs are tailor-made polymeric materials that are able to bind wide range of target analytes and thus have been used in many different fields [38]. These areas include antibody mimics [39], liquid chromatography [40, 41] chemical sensors [42, 43], and solidphase extraction [44-48]. Compared with the other methods, MIPs have the advantages of being inexpensive, showing resistant to elevated temperatures and pressures, and inert toward acids, bases, metal ions, and organic solvents [49]. Besides that, usually MIPs can be reused many times without losing their performance.

Ion-selective sensors have been replacing for a long time other wet analytical methods. They offer high precision and rapidity, low cost of analysis, enhanced selectivity and sensitivity over a wide range of concentrations [50,51]. Still, the sensing material plays a key role in the sensitivity and selectivity of an ion-selective electrode (ISE). The design of sensing materials that are complementary to the size and charge of a particular ion can lead to very selective interactions. Therefore, MIPs may be used advantageously as sensing materials of ion-selective electrodes (ISEs) [52]. In addition, any existing membrane potential does not require the template to be extracted from the membrane, and ionic species do not have to diffuse through the membrane, providing no size restrictions on the template compound [53].

In this work, the development of AMOX MIP-based ISEs was made. The sensors were synthesized with methacrylic acid (MAA), 2-acrylamido-2-methyl-1-propanesulfonic acid (AAMPSO) and vinyl pyridine (VPY) functional monomers, cross-linked by ethylene glycol dimethacrylic acid (EGDMA) within the template molecule. The influence of additives such as potassium tetrakis(4-chlorophenyl)borate (TpClPB) or 4-tert-octylphenol (TOP) was also the target of the study. The sensing materials were included in Poly(vinyl chloride, PVC), plasticized with $o$-nitrophenyl octyl ether (oNPOE), and the corresponding membranes evaluated in steady-state and applied to the analysis of contaminated fish samples.

\section{Experimental}

\section{Apparatus}

All potential measurements were made in a Crison $\mu \mathrm{pH}$ 2002 decimilivoltammeter $( \pm 0.1 \mathrm{mV}$ sensitivity), at room temperature. Constant stirring was guaranteed by means of a Crison, micro ST 2038. The output signal in steady-state evaluations was transferred to a commutation unit and reconnected to one of six ways out, enabling the simultaneous reading of six ISEs. The assembly of the potentiometric cell was as follows: conductive graphite I AMOXselective membrane I buffered solution (Hepes, $1.0 \times 10^{-2}$ $\mathrm{mol} / \mathrm{L}, \mathrm{pH} 5) \|$ electrolyte solution, $\mathrm{KCl}|\mathrm{AgCl}(\mathrm{s})| \mathrm{Ag}$. The reference electrode was an Orion $\mathrm{Ag} / \mathrm{AgCl}$ double-junction (Orion 90-02-00). The selective electrode was prepared in a conventional shape for batch evaluations [52]. The devices had no internal reference solution and epoxy-graphite as used as solid contact.

When necessary, the $\mathrm{pH}$ was measured by a Crison CWL/ S7 combined glass electrode connected to a decimilivoltammeter Crison, pH meter, GLP 22. Fourier transform infrared (FTIR) measurements were conducted in a Nicolet 6700 equipment attached to an Attenuated Total Reflection (ATR) accessory. Spectrophotometric measurements were made in a Thermo Scientific Evolution 300 BB.

\section{Reagents}

All chemicals were of analytical grade, and de-ionized water (conductivity $<0.1 \mu \mathrm{S} \mathrm{cm}^{-1}$ ) was employed. TpClPB, 
$o$ NPOE, TOP (PVC) of high molecular weight, EGDMA, VPY and MAA were purchased from Fluka. Benzoyl peroxide (BPO), methanol (MeOH) and tetrahydrofuran (THF) were obtained from Riedel-deHäen. AMOX, AAMPSO were from sigma-Aldrich. Acetic acid was bought from Carlo Erba.

Synthesis of host-tailored polymers

For preparing MIPs, the template $(0.5$ mmol AMOX) was placed in a glass tube $(14.0 \mathrm{~mm}$ i.d) with the functional monomer (5.0 mmol MAA, $5.0 \mathrm{mmol} \mathrm{VPY}$ and $5.0 \mathrm{mmol}$ AAMPSO), the cross-linker (24.5 mmol EGDMA) and the radical initiator $(0.32 \mathrm{mmol} \mathrm{BPO})$, all dissolved in $3 \mathrm{~mL}$ methanol. The mixture was sonicated, degassed with nitrogen for $5 \mathrm{~min}$, and placed in a water bath at $70{ }^{\circ} \mathrm{C}$ for $30 \mathrm{~min}$. Non-imprinted polymers (NIP) was also prepared in a similar way, excluding the template from the procedure.

The resulting polymers were ground and sieved to particle sizes ranging 50 to $150 \mu \mathrm{m}$. Extraction of the template molecule and washout of non-reacted species was carried out with methanol/acetic acid (4:1, v/v). All polymers (MIP/MAA, NIP/MAA, MIP/AAMPSO, NIP/AAMPSO, MIP/VPY and NIP/VPY were let dry at ambient temperature before use.

\section{Potentiometric sensor}

The sensing membranes were prepared by mixing $200 \mathrm{mg}$ of PVC, $350 \mathrm{mg}$ of $o$ NPOE and $15 \mathrm{mg}$ of the sensing polymer. Some membranes were also added of $7.5 \mathrm{mg}$ of different additives, one acting as anionic additive (TpClPB) and the other enabling hydrogen bridges with the analyte (TOP), typically displaying a cationic behavior for attracting anionic species [54] (Table 1). The mixture was stirred until the PVC was well moistened and dispersed in $3.0 \mathrm{~mL}$ THF. These membranes were placed in conductive supports of conventional shapes. Membranes were let dry for $24 \mathrm{~h}$ and placed in an AMOX solution $1 \times 10^{-3} \mathrm{~mol} / \mathrm{L}$. The electrodes were kept in this solution when not in use.

\section{Potentiometric procedures}

All potentiometric measurements were carried out at room temperature. Emf values of each electrode were measured in solutions of fixed $\mathrm{pH}$ and ionic strength. Increasing concentration levels of AMOX were obtained by transferring $0.0200-5.0 \mathrm{~mL}$ aliquots of AMOX aqueous solutions $1.0 \times 10^{-2} \mathrm{~mol} / \mathrm{L}$ to a $100 \mathrm{~mL}$ beaker containing $50.0 \mathrm{~mL}$ of $1.0 \times 10^{-2} \mathrm{~mol} / \mathrm{L}$ of suitable buffer. Potential readings were recorded after stabilization to $\pm 0.2 \mathrm{mV}$ and emf was plotted as a function of logarithm AMOX concentration. Calibration graphs were used for subsequent determination of unknown AMOX concentrations.

\section{Binding experiments}

The absence of AMOX in the MIP particles was previously confirmed by measuring the absorbance of the washout solution at $230 \mathrm{~nm}$; the particles were repeatedly washed until AMOX was no longer detected. The polymer was dried after at $60{ }^{\circ} \mathrm{C}$ under vacuum until constant weight.

Binding experiments were carried out by placing $20.0 \mathrm{mg}$ of MIP washed particles in contact with $10.0 \mathrm{~mL}$

Table 1 Membrane composition of AMOX sensors casted in $200 \mathrm{mg}$ of PVC and their potentiometric features in $1.0 \times 10^{-2} \mathrm{~mol} \mathrm{\textrm {L } ^ { - 1 }} \mathrm{Hepes}^{-0}$ buffer, $\mathrm{pH} 5$

\begin{tabular}{|c|c|c|c|c|c|c|c|c|c|c|}
\hline \multirow[t]{2}{*}{ ISE } & \multicolumn{4}{|c|}{ Membrane composition } & \multirow{2}{*}{$\begin{array}{l}\text { Slope } \\
\text { (mV/decade) }\end{array}$} & \multirow[t]{2}{*}{$R^{2}(n=5)$} & \multirow{2}{*}{$\begin{array}{l}\mathrm{LOD} \\
(\mathrm{mol} / \mathrm{L})\end{array}$} & \multirow{2}{*}{$\begin{array}{l}\text { LLLR } \\
(\mathrm{mol} / \mathrm{L})\end{array}$} & \multirow[t]{2}{*}{$\sigma_{v}(\mathrm{mV})$} & \multirow[t]{2}{*}{$C v_{w}(\%$} \\
\hline & $\begin{array}{l}\text { Active } \\
\text { ingredient }\end{array}$ & Plasticizer & Additive & Weight (mg) & & & & & & \\
\hline I & MIP/MAA & $o$ NFOE & - & $15: 350$ & $60.73 \pm 2.68$ & 0.999 & $2.94 \times 10^{-5}$ & $4.86 \times 10^{-5}$ & 2.33 & 5.45 \\
\hline II & NIP/MAA & $o \mathrm{NFOE}$ & - & $15: 350$ & $11.89 \pm 4.69$ & 0.994 & $1.82 \times 10^{-5}$ & $3.29 \times 10^{-5}$ & 28.14 & 108.15 \\
\hline III & MIP/MAA & $o \mathrm{NFOE}$ & TpClPB & $15: 350: 7.5$ & $38.91 \pm 12.98$ & 0.975 & $1.85 \times 10^{-4}$ & $2.82 \times 10^{-4}$ & 11.31 & 8.31 \\
\hline IV & MIP/MAA & $o \mathrm{NFOE}$ & TOP & $15: 350: 7.5$ & $57.17 \pm 15.16$ & 0.993 & $3.39 \times 10^{-5}$ & $6.95 \times 10^{-5}$ & 11.46 & 12.37 \\
\hline V & MIP/AAMPSO & $o \mathrm{NFOE}$ & - & $15: 350$ & $5.58 \pm 2.37$ & 0.994 & $3.16 \times 10^{-5}$ & $3.99 \times 10^{-5}$ & 52.33 & 35.17 \\
\hline VI & NIP/AAMPSO & $o \mathrm{NFOE}$ & - & $15: 350$ & $27.98 \pm 8.86$ & 0.995 & $3.35 \times 10^{-5}$ & $1.28 \times 10^{-4}$ & 17.82 & 82.62 \\
\hline VII & MIP/AAMPSO & $o \mathrm{NFOE}$ & TpClPB & $15: 350: 7.5$ & $51.01 \pm 16.33$ & 0.987 & $2.30 \times 10^{-4}$ & $3.75 \times 10^{-4}$ & 5.87 & 2.81 \\
\hline VIII & MIP/AAMPSO & $o \mathrm{NFOE}$ & TOP & $15: 350: 7.5$ & $73.34 \pm 20.84$ & 0.994 & $1.45 \times 10^{-4}$ & $1.66 \times 10^{-4}$ & 37.62 & 19.68 \\
\hline IX & MIP/VPY & $o \mathrm{NFOE}$ & - & $15: 350$ & $51.84 \pm 17.07$ & 0.994 & $2.37 \times 10^{-5}$ & $3.36 \times 10^{-5}$ & 3.54 & 21.83 \\
\hline$X$ & NIP/VPY & $o \mathrm{NFOE}$ & - & $15: 350$ & $50.32 \pm 10.31$ & 0.994 & $1.51 \times 10^{-4}$ & $2.59 \times 10^{-4}$ & 37.76 & 21.74 \\
\hline XI & MIP/VPY & $o \mathrm{NFOE}$ & TpClPB & $15: 350: 7.5$ & $45.86 \pm 10.97$ & 0.981 & $1.90 \times 10^{-4}$ & $2.25 \times 10^{-4}$ & 32.39 & 25.22 \\
\hline XII & MIP/VPY & $o \mathrm{NFOE}$ & TOP & $15: 350: 7.5$ & $55.35 \pm 10.98$ & 0.993 & $4.56 \times 10^{-5}$ & $3.86 \times 10^{-5}$ & 5.16 & 11.57 \\
\hline
\end{tabular}

$C v_{w}$ coefficient variation if weekly calibration for $2.82 \times 10^{-4} \mathrm{~mol} / \mathrm{L}$ 
AMOX solutions ranging $0.2-5.0 \mathrm{mmol} / \mathrm{L}$. The mixtures were stirred for $12 \mathrm{~h}$ at room temperature and the solid phase separated by centrifugation $(3,000 \mathrm{rpm}, 10 \mathrm{~min})$. The concentration of free AMOX in the supernatant was detected by UV spectrophotometry at $230 \mathrm{~nm}$. The amount of AMOX bound to the polymer was calculated by subtracting the concentration of free AMOX from the initial AMOX concentration. The data obtained were used for Scatchard analysis.

\section{FTIR}

The infrared spectra from FTIR spectroscopy were recorded after base line correction, each $30 \mathrm{~min}$, accounting for the correction of the absorption of atmospheric molecules such as carbon dioxide. Each spectrum was the average of 32 scans for the same sample. The plot represented wave number, with a range from 525 to $4,000 \mathrm{~cm}^{-1}$, in function of absorbance. The resolution of the device was 4 .

\section{Determination of AMOX in fish}

Constant weights of well-ground fish $(\sim 2.0 \mathrm{mg})$ from aquaculture origin were transferred to $15-\mathrm{mL}$ tubes. A $10 \mathrm{~mL}$ portion of $0.01 \mathrm{~mol} / \mathrm{L}$ Hepes buffer $\mathrm{pH} 5$ was added and thoroughly mixed with fish sample. A sonication period of $5 \mathrm{~min}$ ensured the extraction of the analyte. The supernatant was obtained by centrifugation at 1,000 rpm and transferred quantitatively to a $25-\mathrm{mL}$ volumetric flask after filtration. Analytical measurements were conducted over this solution after completing the flask to the final volume with buffer.

For AMOX potentiometric analysis, a $25-\mathrm{mL}$ aliquot of the fish solution was used. The direct potential method was applied to AMOX determination in fish samples.

\section{Results and discussions}

It is known that the ionophore or ion carrier is the key element in a polymeric membrane sensor, because the binding strength between it and the target analyte are responsible for the selectivity of the potenciometric sensor [55]. Among several other electroactive materials, MIPs may act as potentiometric sensing materials $[52,56]$. MIPs are based on the formation of stable complexes between templates and their functional monomers, in the reaction mixture, as well as the preservation of these complexes in the resulting polymers. With that propose, mostly covalent bonds have been used for fixation of the template molecules within the tailored cavities. However, fast and reversible binding requires low activation energies. This is achieved by means of non-covalent binding, leading to sites that are less oriented than those in covalent imprinting but still with similar selectivity and sensitivity [57]. So, the association between MIP and ISEs avoid the need of template extraction from the host-tailored particle. This extraction may leave vacant recognition sites, ready for binding, which is a typical source of uncertainty at the determination or a sensitivity-limiting factor.

In this work, electrostatic interactions between AMOX and VPY, AAMPSO or MAA monomers were considered to support the self-assembling of the sensor (that match the shape of AMOX). Mostly hydrogen bonds were established with the template compound. The contribution of monomer, cross-linker and solvent to host-guest binding properties were studied. Figure 1 shows that AMOX has both amino and carboxylic acid functions on its structure. Theoretically, this turns it an ideal compound to interact with MAA, AAMPSO and VPY monomers.

\section{Binding characteristic of the MIP}

To understand the way how small molecules interact with adsorbent surface, the mode of binding and site distributions in the interaction, adsorption isotherms are an important tool. They plot the equilibrium concentrations of bound ligand (adsorbate) versus free ligand. In liquid-phase applications of MIPs, a molecule in solution interacts with binding sites in a solid adsorbent. In the liquid-phase and after equilibrium the free ligand concentration becomes constant and is easily quantified to plot the corresponding adsorption isotherm.

According to that, synthesized particles were left in solutions of several AMOX concentrations under continuous stirring. The results of these equilibrium binding experiments were plotted in Fig. 2a. The corresponding experimental data was used to carry out the Scatchard analysis and estimate the binding parameters of the MIP particles. As revealed in Fig. 2b, the Scatchard plot was not linear in all AMOX concentration range, indicating that the binding sites in the MIP are non-uniform.

Most MIPs suffer from a heterogeneous distribution of binding sites. This binding site heterogeneity results from the amorphous nature of the polymer, with binding sites that are not identical, somewhat similar to a polyclonal preparation of antibodies. The sites may, for instance, reside in domains with different cross-linking density and accessibility.

Scatchard plot (Fig. 2b) shows two distinct sections within the plot that can be regarded as straight lines. This represents two different behaviors of binding sites in the MIP of MAA, AAMPSO and VPY. For the MIP/MAA, the equilibrium dissociation constant $K d$ and the apparent maximum amount $Q_{\max }$ for the higher affinity binding sites are $321 \mu \mathrm{mol} / \mathrm{L}$ and $587 \mu \mathrm{mol} / \mathrm{g}$ for dry polymer, 

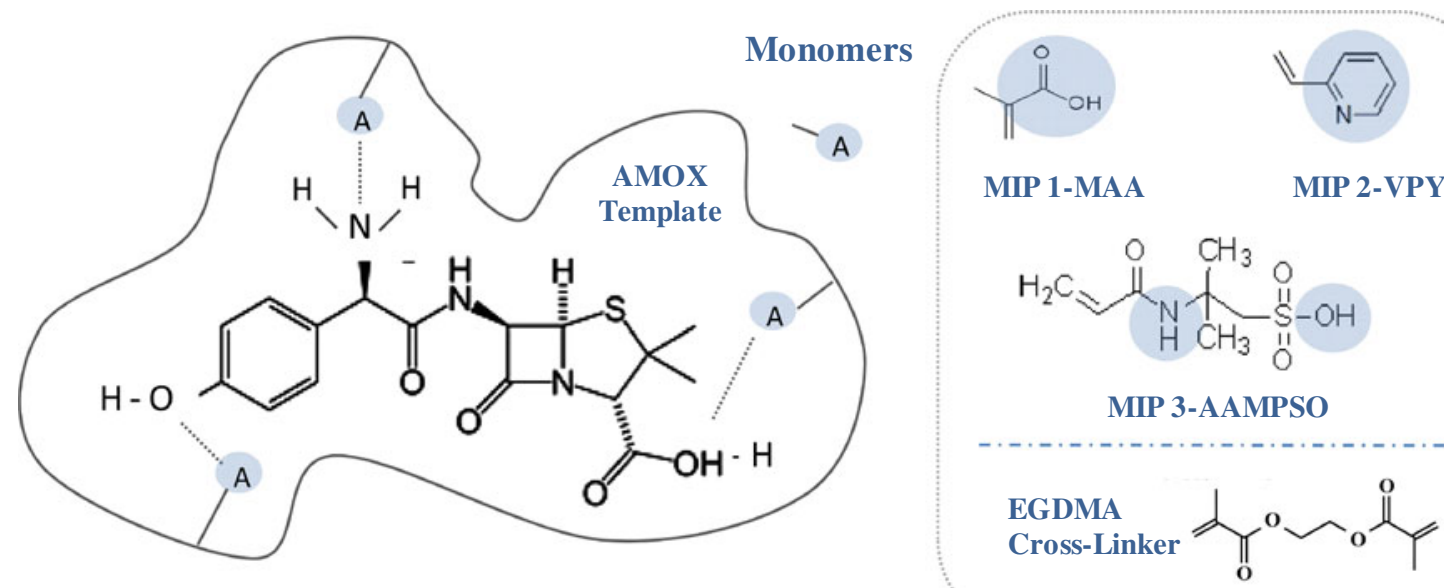

Fig. 1 Chemical structure of monomers, cross-linker and molecularly imprinted polymers showing non-covalent binding sites to AMOX
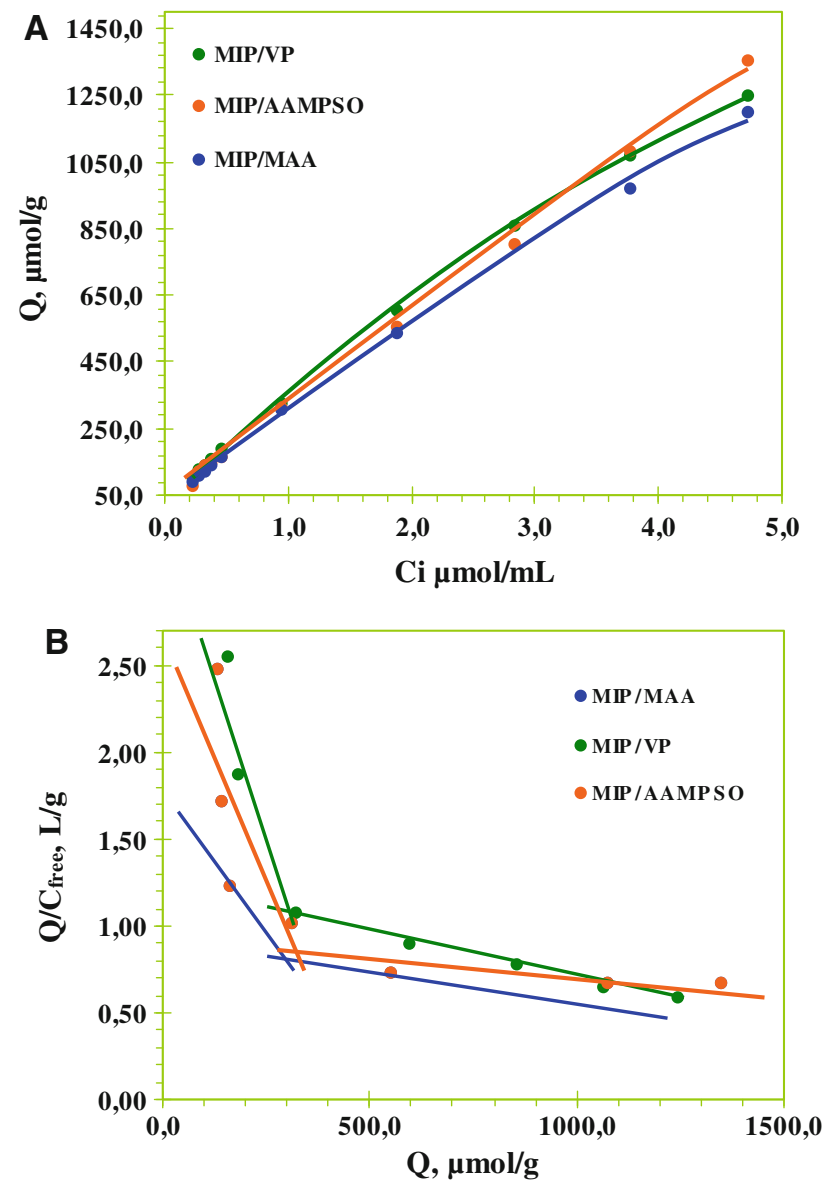

Fig. 2 Binding isotherm (a) and Scatchard plot (b) for AMOX/MAA, AMOX/AAMPSO and AMOX/VPY imprinted polymer. Q is the amount of AMOX bond to $20.0 \mathrm{mg}$ of polymer; $t=25^{\circ} \mathrm{C}$; $V=10.00 \mathrm{~mL}$; binding time: $20 \mathrm{~h}$

respectively. By the same treatment, $K d$ and $Q_{\max }$ for the lower affinity binding sites were $4096 \mu \mathrm{mol} / \mathrm{L}$ and $3,312 \mu \mathrm{mol} / \mathrm{g}$, respectively. Comparatively, for MIP/VPY the equilibrium dissociation constant $K d$ and the apparent maximum amount $Q_{\max }$ for the higher affinity binding sites are $126 \mu \mathrm{mol} / \mathrm{L}$ and $451 \mu \mathrm{mol} / \mathrm{g}$ for dry polymer, $K d$ and $Q_{\max }$ is $1,984 \mu \mathrm{mol} / \mathrm{L}$ and $2,380 \mu \mathrm{mol} / \mathrm{g}$, respectively. Finally, for MIP/AAMPSO the equilibrium dissociation constant $K d$ and the apparent maximum amount $Q_{\max }$ for the higher affinity binding sites are $24 \mu \mathrm{mol} / \mathrm{L}$ and $191 \mu \mathrm{mol} / \mathrm{g}$ for dry polymer, $K d$ and $Q_{\max }$ is $3,572 \mu \mathrm{mol} / \mathrm{L}$ and $3,567 \mu \mathrm{mol} / \mathrm{g}$, respectively.

\section{Sensors performances}

AMOX sensors contained MIP or NIP particles as electroactive materials dispersed in plasticizing solvent and PVC. Characterization of their main analytical features followed IUPAC recommendations [58] and was carried out under static mode of operation. The results obtained are represented in Table 1 and Fig. 3. AMOX sensors based on MIP particles displayed different behaviors in terms of sensitivity and detection limits. MIP sensors prepared with MAA, AAMPSO and VPY showed, respectively, linear response starting at $4.86 \times 10^{-5}, 3.99 \times 10^{-5}$ and $3.36 \times$ $10^{-5} \mathrm{~mol} / \mathrm{L}$ AMOX, cationic slopes of $60.7 \pm 2.7$, $55.8 \pm 2.4$ and $51.8 \pm 17.1 \mathrm{mV} /$ decade and detection limits of $2.9 \times 10^{-5}, 3.2 \times 10^{-5}$ and $2.4 \times 10^{-5} \mathrm{~mol} / \mathrm{L}$. The corresponding NIP particles with monomer MAA and AAMPSO displayed worse response than the response of VPY sensor that presented a linear response starting at $2.59 \times 10^{-4} \mathrm{~mol} / \mathrm{L}$ AMOX, cationic slope of $50.32 \pm$ $10.31 \mathrm{mV} /$ decade and detection limits of $1.51 \times 10^{-4}$ $\mathrm{mol} / \mathrm{L}$. In general terms, near-Nernstian behavior was observed only for MIP sensors excepting for sensor with MAA monomers added of anionic additive (TpClPB) and AAMPSO, while the other sensors showed widest linear response range. To improve the operating features of the 
previous membranes, the MIP-based sensors were added of an anionic and cationic lipophilic compound. Usually, the addition of these compounds of lipophilic nature to potentiometric sensors reduces the anionic or cationic interference and lowers the electrical resistance of the membranes [59].

In this work, TpClPB and TOP were added to the selective membrane, giving respectively anionic charges to the membrane phase or displaying a "similar to cationic" effect in the membrane (Table 1). The sensors based on MIP/MAA, MIP/AAMPSO and MIP/VPY with TOP showed linear response ranges starting from $6.95 \times 10^{-5}$, $1.66 \times 10^{-4}$ and $3.86 \times 10^{-5} \mathrm{~mol} / \mathrm{L}$, detection limits with $3.39 \times 10^{-5}, 1.45 \times 10^{-4}$ and $4.56 \times 10^{-5} \mathrm{~mol} / \mathrm{L}$, and cationic slopes of $57.17 \pm 15.16,73.34 \pm 20.84$ and $55.35 \pm 10.98 \mathrm{mV} /$ decade, respectively. Both MAA- and VPY-based sensors presented near-Nernstian slope while the AAMPSO sensor showed a supra-Nernstian behavior (Fig. 3).

Moreover, the AAMPSO- and VPY-based sensors with the additive TpCIPB presented a linear response starting at $3.75 \times 10^{-4}$ and $2.25 \times 10^{-4} \mathrm{~mol} / \mathrm{L}$ AMOX, cationic slopes of $51.01 \pm 16.33$ and $45.86 \pm 10.97 \mathrm{mV} /$ decade and detection limits of $2.30 \times 10^{-4}, 1.90 \times 10^{-4} \mathrm{~mol} / \mathrm{L}$, respectively. The MAA sensor with the same additive displayed worse response than without additive, presenting a linear behavior starting at $2.82 \times 10^{-4} \mathrm{~mol} / \mathrm{L}$, a cationic slope of $38.91 \pm 12.98 \mathrm{mV} /$ decade and detection limit $1.85 \times 10^{-4} \mathrm{~mol} / \mathrm{L}$. Comparing the results obtained for the

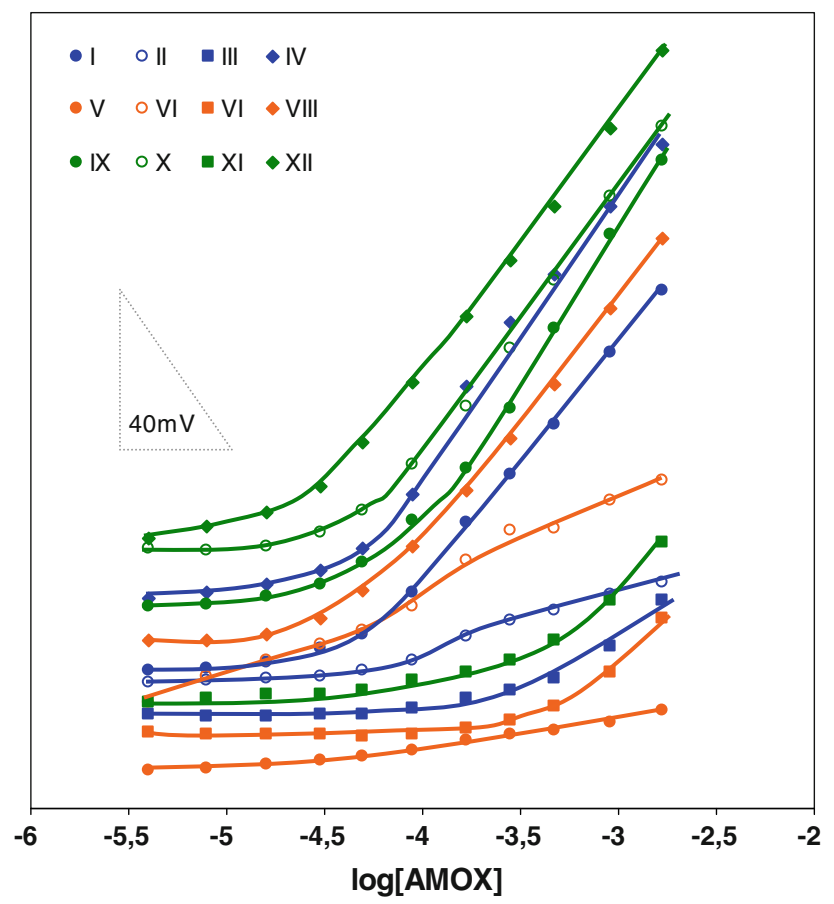

Fig. 3 Potentiometric response of AMOX PVC membrane sensors under static mode of operation in $0.01 \mathrm{~mol} / \mathrm{L}$ Hepes buffer, $\mathrm{pH} 5$ corresponding sensor with or without additive, a significant improvement in terms of slope was observed for VPY sensors, but the value of lower limit of linear range increased. The anionic additive did not improve the behavior of the sensor in terms of slope. The performance of sensor with monomer AAMPSO improved in the presence of both additives in terms of slope, detection limit and even in linearity. So, comparing the responses of the sensors without cationic or anionic additive, it seemed to show that the only responsible for this is the additive. The behavior of the sensor MAA became worse with the addition of both cationic and anionic additive in terms of slope, lower limit of linear range and even the detection limit.

Considering the previous observations, the selective sensor based on MAA combined the best analytical performance, showing the best slope and limit of detection.

Effect of amoxicillin degradation products

The experimental determinations were made in $\mathrm{pH} 4-5$. In acid medium, AMOX is positively charged in its amine function but its degradation may occur, opening the fourmembered $\beta$-lactam ring and yielding the product amoxicillin penicilloic acid. Assuming this compound as the major degradation product of AMOX, it may interfere with the response of the ISE by means of its amine group (positively charged in acidic media) and due to structure similarities with the main analyte. This was not observed when repeated calibrations were made with the same AMOX standard solution for two days. Thus, either amoxicillin penicilloic acid does not affect the response of the potentiometric sensor or it displays the same sensitivity as AMOX itself. Considering that the proposed sensor is used for screening AMOX in fish samples, if this last condition occurs, a positive error is generated and no serious risk posed to human safety.

Further degradation of amoxicillin penicilloic acid is the formation of a new, stable, six-membered ring giving diketopiperazine amoxicillin in low amounts. This compound does not have the amino group (responsible for the potential difference across the membrane), and thus this degradation product does not interfere in the AMOX detection.

Response time and lifetime

The time required to achieve a steady potential response $( \pm 3 \mathrm{mV})$ using the proposed sensors in $1.96 \times 10^{-4}$ to $7.41 \times 10^{-4} \mathrm{~mol} / \mathrm{L}$ AMOX solutions with a rapid tenfold increase in concentration was $<20 \mathrm{~s}$. After the replicate calibrations of each sensor, low potential drift, long-term stability and negligible change in the response was observed. The sensors were stored and conditioned in 
$10^{-3} \mathrm{~mol} / \mathrm{L}$ AMOX solution. With all sensors examined, the detection limits, response times, linear ranges and calibration slopes were reproducible of their original values over a period of at least 4 weeks.

\section{Effect of $\mathrm{pH}$}

The two dissociate constants $\left(\mathrm{pK}_{\mathrm{a}}\right)$ of AMOX are 2.4 and 7.3 , respectively [60]. The significant effect of $\mathrm{pH}$ occurred in the range of 3.0-6.0 as shown in Fig. 4. This result was most probably due to the presence of AMOX in amphiprotic
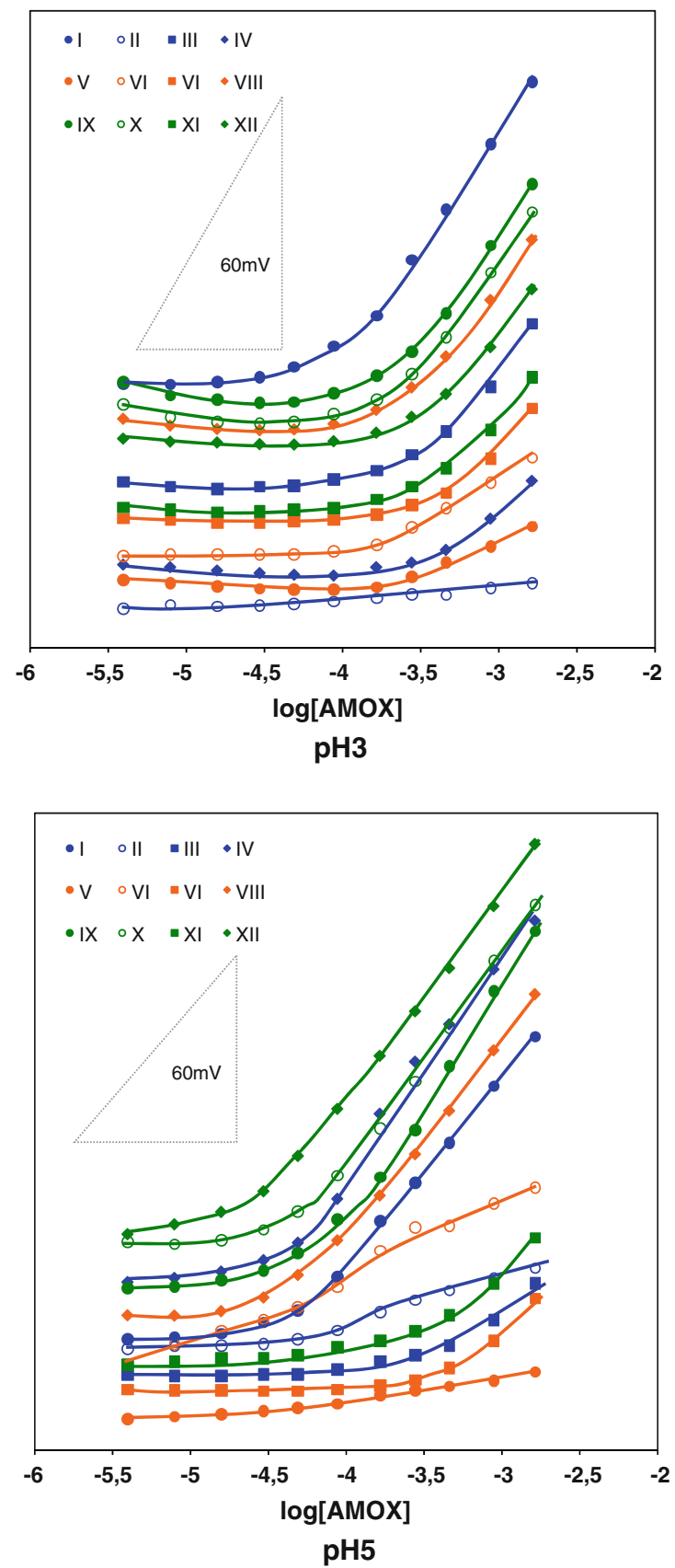

form. The wider linear ranges with lower detection limits were observed at $\mathrm{pH} 5$. Thus, all subsequent studies were carried at this $\mathrm{pH}$, adjusted by a $0.01 \mathrm{~mol} / \mathrm{L}$ Hepes buffer solution.

Sensor selectivity

One of the most important potentiometric features in analytical application is the chemical selectivity of a sensor. One component of the selective membrane that exerts great influence upon this property is the electroactive material, as
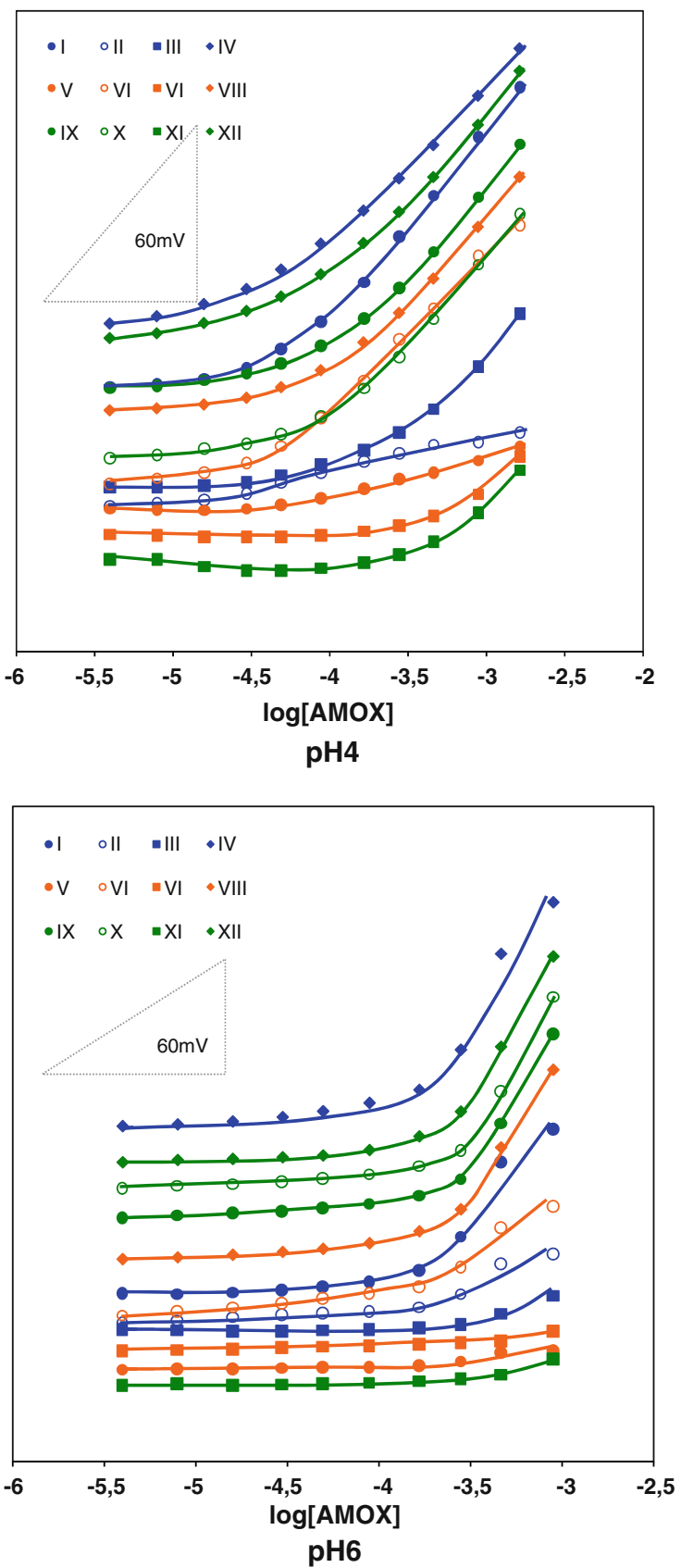

Fig. 4 Influence of $\mathrm{pH}$ in sensors response 
Fig. 5 Potentiometric selectivity coefficients (log $K^{\mathrm{POT}}$ ) by separation solutions method, of AMOX membranebased sensors, in $0.01 \mathrm{~mol} / \mathrm{L}$ Hepes buffer, pH 5

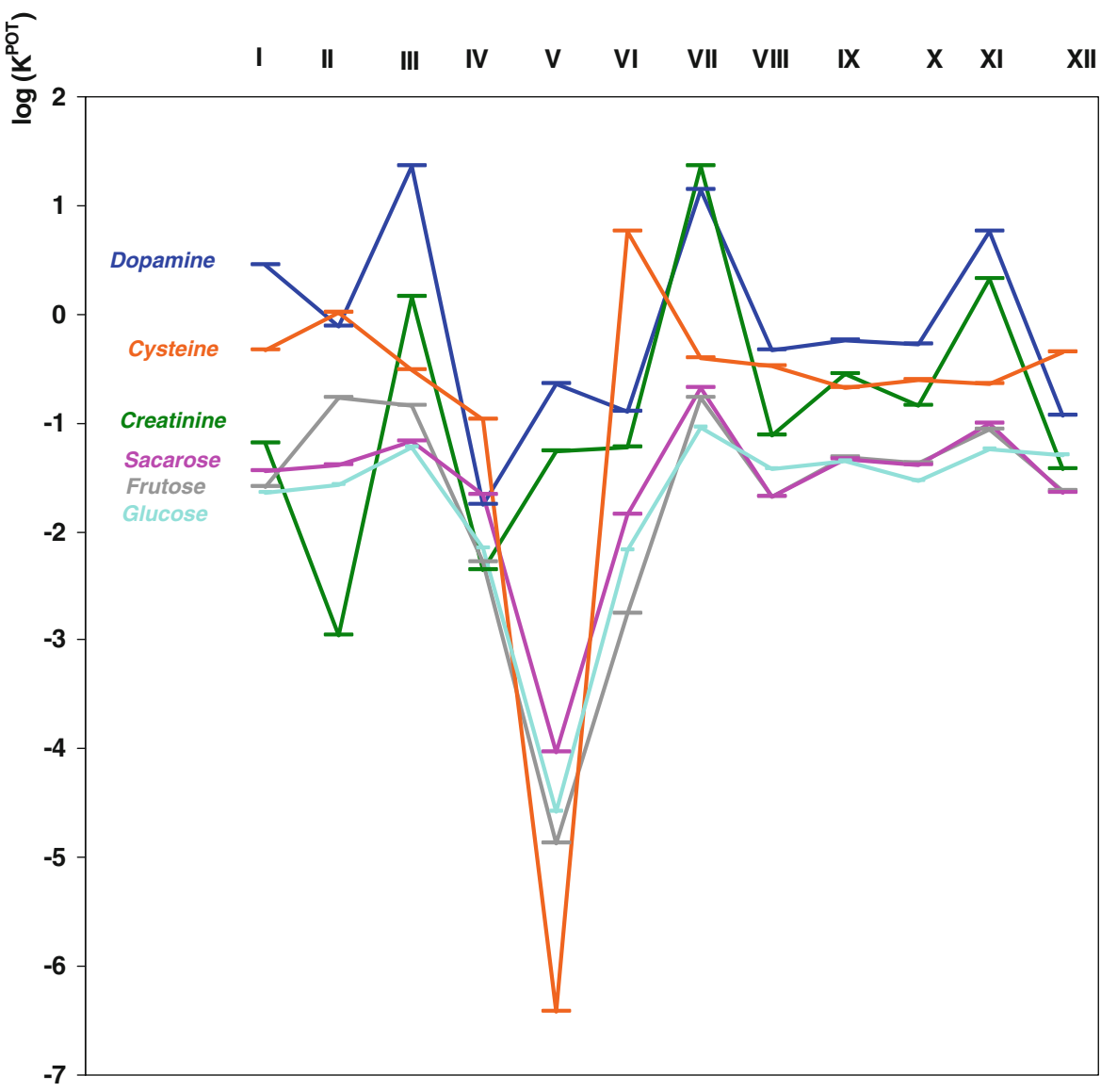

the mechanism of selectivity is mainly governed by stereospecific and electrostatic aspects. Thus, a different behavior is expected for each sensor.

Potentiometric selectivity coefficients were assessed for this purpose by the separate solution method (SSM) and used to compare selectivity properties of AMOX sensors. $\log \mathrm{K}^{\mathrm{POT}}$ values were plotted in Fig. 5 and indicated the degree of preferential interaction for AMOX over different organic and inorganic species, common in biological and food samples. The former group included dopamine (DP), used in aquaculture, sacarose (Sac), frutose (Fru), glucose (Glu), cysteine (Cys), and creatinine $\left(\mathrm{Ct}^{+}\right)$.

In general, all the sensors showed a different behavior in terms of $\log \mathrm{K}^{\mathrm{POT}}$. ISE based on MAA sensing materials and in the presence of anionic additive showed that the compound dopamine had the biggest interference in terms of selectivity and glucose the lower. The sensor MIP with the monomer MAA and TOP additive, as well as the corresponding NIP, showed that the compound cysteine is the one that had bigger interference in AMOX determination and the creatinine had lower influence on it. The sensor based on AAMPSO showed a different behavior for all MIPs and NIP. Comparatively, the sensor MIP with monomer VPY only and in the presence of anionic additive as well as NIP showed that the compound glucose had lower and dopamine more interference in terms of selectivity. The sensor MIP with monomer VPY but with TOP additive showed a different behavior, sacarose was the compound with lower and cysteine with more interference in terms of selectivity, in the determination of AMOX concentration.

The selectivity order for ISE I, sensor based on MAA sensing materials was DP $\gg \mathrm{Cys} \gg \mathrm{Ct}^{+}>\mathrm{SAC}>\mathrm{Fru}>$ Glu, for ISE II the corresponding sensor but contained NIP particles, sensor II, was $\mathrm{Ct}^{+} \gg \mathrm{DP} \gg \mathrm{Fru} \gg \mathrm{Sac}>\mathrm{Glu} \gg$ Cys. The behavior of ISE III and IV with both MAA monomer and TpClPB and TOP additive displayed the following order of $\log \mathrm{K}^{\mathrm{POT}}$ : $\mathrm{DP} \gg \mathrm{Ct}^{+} \gg \mathrm{Cys}>\mathrm{Fru} \gg$ $\mathrm{Sac}>\mathrm{Glu}$ and $\mathrm{Cys} \gg \mathrm{Sa} \approx \mathrm{DP} \gg \mathrm{Glu}>\mathrm{Fru}>\mathrm{Ct}^{+}$, respectively. The selectivity order for ISE $\mathrm{V}$, sensor based on AAMPSO sensing materials was DP $\gg \mathrm{Ct}^{+} \gg \mathrm{Sac}>$ Glu $>$ Fru $\gg$ Cys, and the corresponding NIP (ISE VI) present the following order Cys $>\mathrm{DP}>\mathrm{Ct}^{+}>\mathrm{Sac} \gg$ Glu $\gg$ Fru. The ISE VII and VIII with the monomer AAMPSO added of TpCIPB and TOP additive present the $\log \mathrm{K}^{\mathrm{POT}}$ sequences of $\mathrm{Ct}^{+}>\mathrm{DP} \gg \mathrm{Cys}>\mathrm{Sac}>$ Fru $>$ Glu and $\mathrm{DP} \gg \mathrm{Ct}^{+} \gg \mathrm{Cys}>\mathrm{Glu}>\mathrm{Sac}$ "Fru, respectively.

The ISE IX prepared with sensor based on VPY sensing materials presented $\log \mathrm{K}^{\mathrm{POT}}$ order of $\mathrm{DP} \gg$ $\mathrm{Ct}^{+}>\mathrm{Cys} \gg \mathrm{Fru} \approx \mathrm{Sac} \approx \mathrm{Glu}$ to the same sensor 
added of TpCIPB and TOP their $\log \mathrm{K}^{\mathrm{POT}}$ sequences were $\mathrm{DP} \gg \mathrm{Ct}^{+} \gg \mathrm{Cys} \gg \mathrm{Sac} \approx$ Fru $>$ Glu and $\mathrm{Cys} \gg$ $\mathrm{DP} \gg \mathrm{Glu}>\mathrm{Ct}^{+}>$Fru $\approx$ Sac. The ISE X contained NIP particles in the sensing material and with the same monomer presents the following $\log \mathrm{K}^{\text {pot }}$ sequence $\mathrm{DP} \gg \mathrm{Cys} \gg \mathrm{Ct}^{+} \gg \mathrm{Fru} \approx \mathrm{Sac}>\mathrm{Glu}$.

Generally, the addition of TpCIPB decreased the selectivity of the membranes when compared to the TOP additive, the later acting probably as a kind of cationic excluder. Sensors based on MIP AAMPSO and MIP/MAA added of TOP additive provided the lower $\log \mathrm{K}^{\mathrm{POT}}$. Compounds with the amine group seemed to interfere more than others without that group, but only in some ISEs. Although these compounds of positively charged nitrogen atoms presented more similarities to the chemical structure of the main ion, their logarithm selectivity coefficients were mostly below -1 . This suggested small interference in these ISEs from parent compounds of positively charged nitrogen atoms, being the binding to AMOX the prevailing process. In general, negligible interference was observed in some AMOX-selective electrodes, enabling their application in the analysis of fish.

\section{FTIR}

Selectivity of imprinted polymers is ensured by the formation of stable complexes between templates and their functional monomers in the reaction mixture as well as their preservation in the resulting polymers. However, energies of covalent binding are often too high for fast and reversible binding. Electrostatic interaction with template molecules should be suitable for potentiometric transducers. As the best monomer was MAA, FTIR analysis was made just for it and the template molecule, AMOX. MAA monomers establish hydrogen bonds with template molecules. FTIR analysis is used to confirm the similarities between produced particles of MIP and NIP. As we can see in Fig. 6, the peaks that originated strong absorption bands around $1,100 \mathrm{~cm}^{-1}$ indicated the ester function from the cross-linker. The strong absorbance at $1,600 \mathrm{~cm}^{-1}$ was due

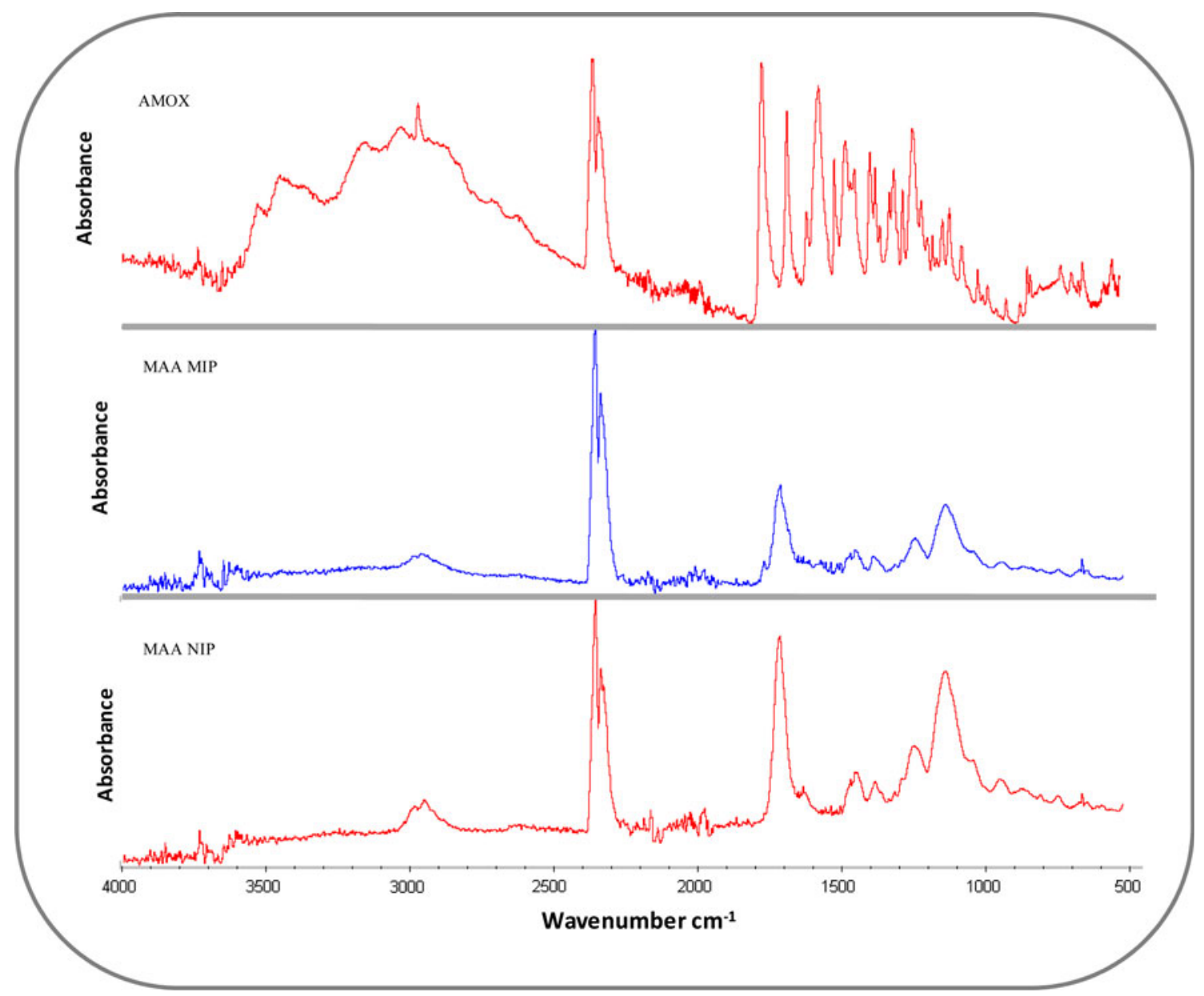

Fig. 6 FTIR spectra of AMOX and MIP and NIP polymers of MAA (average of 32 scans from 525 to $4,000 \mathrm{~cm}^{-1}$, with background correction, and room temperature/humidity control) 
Table 2 Potentiomeric determination of AMOX in fish using MAA/MIP-based membrane sensor

\begin{tabular}{|c|c|c|c|c|c|c|}
\hline \multirow[t]{2}{*}{ Sample } & \multirow[t]{2}{*}{$\mu \mathrm{g} \mathrm{AMOX} / \mathrm{mL}$} & \multirow[t]{2}{*}{$t$-student } & \multirow[t]{2}{*}{$p$ tailed } & \multicolumn{3}{|l|}{ Found $\mu \mathrm{g} / \mathrm{mL}$} \\
\hline & & & & Batch & Recovery (\%) & Relative error $(\%)$ \\
\hline \multirow[t]{4}{*}{ Fish } & 30 & 3.18 & 0.06 & $32.30 \pm 2.4$ & $107.66 \pm 7.90$ & 7.67 \\
\hline & 60 & & & $60.18 \pm 1.4$ & $100.30 \pm 2.30$ & 0.30 \\
\hline & 90 & & & $91.21 \pm 0.2$ & $101.34 \pm 0.58$ & 1.34 \\
\hline & 115 & & & $117.51 \pm 1.2$ & $102.19 \pm 1.04$ & 2.18 \\
\hline
\end{tabular}

to the carboxylic group in MAA. The MIP polymer did not show residues of AMOX, which was confirmed by comparing it with the NIP FTIR spectrum.

Analytical application: monitoring of AMOX in fish samples

The results of the potentiometric analysis conducted in steady-state showed recoveries ranging between 100.3 and $107.7 \%$ with an average relative standard deviation of 2.3 and $7.9 \%$, respectively. Fish samples doped with $90 \mu \mathrm{g}$ AMOX $/ \mathrm{mL}$ displayed the lowest standard deviation, $\pm 0.2 \mu \mathrm{g} / \mathrm{mL}$. As presented in Table 2, the results obtained for the analysis of fish samples presented a good accuracy. To confirm whether there was a statistically significant difference between the means of static potentiometric sets of results, the $t$-student value was calculated. The $p$ two-tail was 0.06 , below the theoretical value (3.18), confirming that there are no significant differences between the means.

\section{Conclusions}

Molecular imprinting technique was employed to produce AMOX host-tailored sensors for potentiometric transduction. Different monomers like MAA, AAMPSO, and VPY were used to produce different MIP materials. MAA- and VPY-based sensors displayed good potentiometric analytical features capable of discriminating other antibiotics in aqueous media, in the opposite of the AAMPSO. Simplicity in designing, short measurement time, good precision, high accuracy, high analytical throughput, low detection limit and good selectivity are the advantages of these sensors.

The sensor MIP/MAA was the one showing better response and was successfully applied in analysis of AMOX in fish samples. The proposed method is simple, of low cost, precise, accurate and inexpensive regarding reagent consumption and equipment involved. Wastewaters discharged are of small concern to environment regarding its volume and composition. This method produces quicker response for AMOX than those provided by microbiological methods and are much less expensive than the chromatographic methods that are used for routine purposes.

The main goal of this new sensor is to be used as a screening method; however, its detection limit is still higher than desire. One direction to solve this dilemma could be the use of pre-concentration procedures such as solid-phase extraction (SPE) to increase the concentration levels of the analyte in the analyzed sample. Another alternative is the use of the same membranes applied over miniaturized devices.

Acknowledgments The authors acknowledge the financial support from FCT, Fundação para a Ciência e Tecnologia, by means of project PTDC/AGR-AAM/68359/2006.

\section{References}

1. Woodward KN (2004) In: Watson DH (ed) Pesticide, Veterinary and Other Residues in Food. CRC Press, Boca Raton. FL, pp $157-174$

2. Botsoglou NA, Fletouris DJ (2004) In: Nollet LML (ed) Handbook of Food Analysis, Residues and Other Food Component Analysis. Marcel Dekker, Ghent, pp 931-1037

3. Shoukry AF, Issa YM, Rizk MS, Abdelaal MM (1994) Amoxycillinium-selective plastic membrane electrodes based on amoxycillinium-phosphotungstate ion associate. Electroanalysis 6:914-917

4. Cole DW, Cole R, Gaydos SJ, Gray J, Hyland G, Jacques ML, Powell-Dunford N, Sawhney C, Au WW (2009) Aquaculture: environmental, toxicological, and health issues. Int J Hyg Environ Health 212:369-377

5. Frappaolo PJ, Guest GB (1986) Regulatory status of tetracyclines, penicillin and other antimicrobial microbials drugs in animal feeds. J Anim Sci 62:86-92

6. Cass QB, Gomes RF, Calafatti SA, Pedrazolli J Jr (2003) Determination of amoxycillin in human plasma by direct injection and coupled-column high-performance liquid chromatography. J Chromatogr A 987:235-241

7. Menelaou A, Somogyi AA, Barclay ML, Bochner F (1999) Simultaneous quantification of amoxycillin and metronidazole in plasma using high-performance liquid chromatography with $\mathrm{q}$ photodiode array detection. J Chromatogr B 731:261-266

8. Rezaei B, Damiri S (2009) Electrochemistry and adsorptive stripping voltammetric determination of amoxicillin on a multiwalled carbon nanotubes modified glassy carbon electrode. Electroanalysis 21:1577-1586

9. Anfossi P, Zaghini A, Grassigli G, Menotta S, Fedrizzi G (2002) Relative oral bioavailability of microgranulated amoxicillin in pigs. J Vet Pharm Ther 25:329-334 
10. Reyns T, Cherlet M, De Baere S, De Backer P, Croubels S (2008) Rapid method for the quantification of amoxicillin and its major metabolites in pig tissues by liquid chromatography-tandem mass spectrometry with emphasis on stability issues. J Chromatogr B 861:108-116

11. Ang CYW, Liu FF, Lay JO Jr, Luo W, McKim K, Gehring T, Lochmann R (2000) Liquid chromatographic analysis of incurred amoxicillin residues in catfish muscle following oral administration of the drug. J Agric Food Chem 48:1673-1677

12. Grant A, Briggs AD (1998) Use of ivermectin in marine fish farms: some concerns. Marine pollution bulletin. Mar Pollut Bull 36:566-568

13. Costelloe M, Costelloe J, O'Connor B, Smith P (1998) Densities of polychaetes in sediments under a salmon farm using Ivermectin. Bull Eur Ass Fish Path 18:22-25

14. García-Reiriz A, Damiani PC, Olivieri AC (2007) Different strategies for the direct determination of amoxicillin in human urine by second-order multivariate analysis of kinetic-spectrophotometric data. Talanta 71:806-815

15. García-Reiriz A, Damiani PC, Olivieri AC (2007) Analysis of amoxicillin in human urine by photo-activated generation of fluorescence excitation-emission matrices and artificial neural networks combined with residual bilinearization. Anal Chim Acta 588:192-199

16. Mohamed GG (2001) Spectrophotometric determination of ampicillin, dicluxacillin, flucloxacillin and amoxicillin antibiotic drugs: ion-pair formation with molybdenum and thiocyanate. J Pharm Biomed Anal 24:561-567

17. Pasamontes A, Callao MP (2004) Determination of amoxicillin in pharmaceuticals using sequential injection analysis and multivariate curve resolution. Anal Chim Acta 515:159-165

18. Salem H (2004) Selective spectrophotometric determination of phenolic-lactam antibiotics in pure forms and in their pharmaceutical formulations. Anal Chim Acta 515:333-341

19. Al-Abachi MQ, Haddi H, Al-Abachi AM (2005) Spectrophotometric determination of amoxicillin by reaction with $N$, $N$-dimethyl- $p$-phenylenediamine and potassium hexacyanoferrate(III). Anal Chim Acta 554:184-189

20. Santos SM, Henriques M, Duarte AC, Esteves VI (2007) Development and application of a capillary electrophoresis based method for the simultaneous screening of six antibiotics in spiked milk samples. Talanta 71:731-737

21. Pajchel G, Pawłowski K, Tyski S (2002) CE versus LC for simultaneous determination of amoxicillin/clavulanic acid and ampicillin/sulbactam in pharmaceutical formulations for injections. J Pharm Biomed Anal 29:75-81

22. Uslu B, Biryol I (1999) Voltammetric determination of amoxicillin using a poly ( $N$-vinyl imidazole) modified carbon paste electrode. J Pharm Biomed Anal 20:591-598

23. Bergamini MF, Teixeira MFS, Dockal ER, Bocchi N, Cavalheiro ETG (2006) Evaluation of different voltammetric techniques in the determination of amoxicillin using a carbon paste electrode modified with [ $N, N$-ethylenebis(salicylideneaminato)] oxovanadium(IV). J Electrochem Soc 153:E94-E98

24. Santos DP, Bergamini MF, Zanoni MVB (2008) Voltametric sensor for amoxicillin determination in human urine using polyglutamic acid/glutaraldehyde film. Sens Actuators B 133:398-403

25. Matar KM (2006) Simple and rapid LC method for the determination of amoxicillin in plasma. Chromatographia 64:255-260

26. Tavakoli N, Varshosaz J, Dorkoosh F, Zargarzadeh MR (2007) Development and validation of a simple HPLC method for simultaneous in vitro determination of amoxicillin and metronidazole at single wavelength. J Pharm Biomed Anal 43:325-329

27. Li W, Tan F, Zhao K (2006) Simultaneous determination of amoxicillin and ranitidine in rat plasma by high-performance liquid chromatography. J Pharm Biomed Anal 41:594-598
28. De Baere S, De Backer P (2007) Quantitative determination of amoxicillin in animal feed using liquid chromatography with tandem mass spectrometric detection. Anal Chem Acta 586:319-325

29. Foroutan SM, Zarghi A, Shafaati A, Khoddamc A, Movahed H (2007) Simultaneous determination of amoxicillin and clavulanic acid in human plasma by isocratic reversed-phase HPLC using UV detection. J Pharm Biomed Anal 45:531-534

30. Ang CYW, Luo W, Hansen EB Jr, Freeman JP, Thompson HC Jr (1996) Determination of amoxicillin in catfish and salmon tissues by liquid chromatography with precolumn formaldehyde derivatization. J AOAC Inter 79:389-396

31. Muth P, Metz R, Beck H, Bolten W, Vergin H (1996) Improved high-performance liquid chromatographic determination of amoxicillin in human plasma by means of column switching. J Chromatogr A 729:26-259

32. Yuan Z, Russlie H, Canafax D (1995) Sensitive assay for measuring amoxicillin in human plasma and middle ear fluid using solid-phase extraction and reversed-phase high-performance liquid chromatography. J Chromatogr B 674:93-99

33. Wibawa J, Fowkes D, Shaw P, Barrett D (2002) Measurement of amoxicillin in plasma and gastric samples using high-performance liquid chromatography with fluorimetric detection. J Chromatogr B 774:141-148

34. Miyazaki K, Ohtani K, Sunada K, Arita T (1983) Determination of ampicillin, amoxicillin, cephalexin, and cepharadine in plasma by high-performance liquid chromatography using fluorometric detection. J Chromatogr B 276:478-482

35. Mascher H, Kikuta C (1998) Determination of amoxicillin in human serum and plasma by high-performance liquid chromatography and on-line postcolumn derivatisation. J Chromatogr A $812: 221-226$

36. Wulff G (2002) Enzyme-like catalysis by molecularly imprinted polymers. Chem Rev 107:1-27

37. Vlatakis LG, Andersson I, Muller R, Mosbach K (1993) Drug assay using antibody mimics made by molecular imprinting. Nature 361:645-647

38. Beltran A, Marc RM, Cormack PAG, Sherrington DC, Borrull F (2008) Selective solid-phase extraction of amoxicillin and cephalexin from urine samples using a molecularly imprinted polymer. J Sep Sci 31:2868-2874

39. Ye L, Mosbach K (2001) Molecularly imprinted microspheres as antibody binding mimics. React Funct Polym 48:149-157

40. Sellergren B (2001) Imprinted chiral stationary phases in high performance liquid chromatography. J Chromatogr A 906:227-252

41. Peter S, Schweitz L, Nilsson S (2003) Molecularly imprinted polymers in capillary electrochromatography: recent developments and future trends. Electrophoresis 24:3892-3899

42. Marx S, Zaltsman A, Turyan AI, Mandler D (2004) Parathion sensor based on molecularly imprinted sol-gel films. Anal Chem $76: 120-126$

43. Kriz O, Ramstrom O, Mosbach K (1997) Molecular imprinting: new possibilities for sensor technology. Anal Chem 69:345A$349 \mathrm{~A}$

44. Rao TP, Daniel S, Gladis JM (2004) Tailored materials for preconcentration or separation of metals by ion-imprinted polymers for solid-phase extraction (IIP-SPE). Trends Anal Chem 23:28-35

45. Xiong Y, Zhou H, Zhang Z, He D, He C (2006) Molecularly imprinted on-line solid-phase extraction combined with flowinjection chemiluminescence for the determination of tetracycline. Analyst 131:829-834

46. Andersson LI (2000) Molecular imprinting for drug bioanalysis: a review on the application of imprinted polymers to solid-phase extraction and binding assay. J Chromatogr B 739:163-173 
47. Qiao F, Sun H, Yan H, Row KH (2006) Molecularly imprinted polymers for solid phase extraction. Chromatographia 64:625-634

48. Ariffin MM, Miller EI, Cormack PAG, Anderson RA (2007) Molecularly imprinted solid-phase extraction of diazepam and its metabolites from hair samples. Anal Chem 79:256-262

49. Xiong Y, Zhou HJ, Zhang ZJ, He DY, He C (2006) Molecularly imprinted on-line solid-phase extraction combined with flow injection chemiluminescence for the determination of tetracycline. Analyst 131:829-834

50. Cosofret VV, Buck RP (1993) Recent advances in pharmaceutical analysis with potentiometric membrane sensors. Crit Rev Anal Chem 24:1-58

51. Bakker E, Malinowaska E, Schiller RD, Meyerhoff ME (1994) Anion-selective membrane electrodes based on metalloporphyrins-the influence of lipophilic and cationic sites on potentiometric selectivity. Talanta 41:881-890

52. Kamel AH, Moreira FTC, Almeida SAA, Sales MGF (2008) Novel potentiometric sensors of molecular imprinted polymers for specific binding of chlormequat. Electroanalysis 20:194-202

53. López MCB, Castañón MJL, Ordieres AJM, Blanco PT (2004) Electrochemical sensors based on molecularly imprinted polymers. Trends Anal Chem 23:36-48
54. Lima JLFC, Montenegro MCBSM, Sales MGF (1996) Benzoate ion-selective electrode with improved selectivity and reproducibility for benzoate determination in medicinal syrups, Mikrochim. Acta 124:35-41

55. Faridbod F, Ganjali MR, Dinarvand R, Norouzi P (2008) Developments in the field of conducting and non-conducting polymer based potentiometric membrane sensors for ions over the past decade. Sensors 8:2331-2412

56. Hutchins RS, Bachas LG (1995) Nitrate-selective electrode developed by electrochemically mediated imprinting doping of polypyrrole. Anal Chem 67:1654-1660

57. Dickert FL, Hayden O (1999) Molecular imprinting in chemical sensing. Trends Anal Chem 18:192-199

58. AC IUP (2000) Analytical chemistry division commission on analytical nomenclature. Pure Appl Chem 72:1851-2082

59. Telting-Diaz M, Bakker E (2001) Effect of lipophilic ionexchanger leaching on the detection limit of carrier-based ionselective electrodes. Anal Chem 73:5582-5589

60. Soto A, Arce A, Khoshkbarchi MK (2005) Partitioning of antibiotics in a two-liquid phase system formed by water and a room temperature ionic liquid. Separ Purif Tech 44:242-246 